\title{
Optimizing the Diagnostic Role of Alpha-Fetoprotein and Abdominal Ultrasound by Adding Overexpressed Blood mRNA Matrix Metalloproteinase-12 for Diagnosis of HCV-Related Hepatocellular Carcinoma
}

\author{
Esam Elshimi $^{a} \quad$ Mostafa Abdel-Samed Mostafa Sakr ${ }^{b}$ \\ Wesam Saber Morad $^{c}$ Lobna Mohammad ${ }^{b}$ \\ ${ }^{a}$ Hepatology Department, National Liver Institute, Menoufia University, \\ Shebin Al-Kom, Egypt; ${ }^{b}$ Genetic Engineering Institute, Sadat University, Sadat, Egypt; \\ ${ }^{c}$ Community Department, National Liver Institute, Menoufia University, \\ Shebin Al-Kom, Egypt
}

\section{Keywords}

Hepatocellular carcinoma - Tumor markers · Alpha-fetoprotein · Matrix metalloproteinase-12

\begin{abstract}
Background and Aims: Matrix metalloproteinase-12 (MMP-12) is involved in tumor invasiveness and metastasis and significantly overexpressed in hepatocellular carcinoma (HCC) tissues. We aimed to investigate the diagnostic and prognostic value of blood mRNA MMP-12 overexpression in patients with HCC. Patients and Methods: From January 2017 to June 2017, 100 patients with HCC (HCV-related cirrhosis) and 100 patients with HCV-related cirrhosis (without HCC) were included in this study. All patients were subjected to triphasic CT abdomen when indicated, liver profile, alpha-fetoprotein (AFP), and molecular characterization of metalloproteinase-12 expression. Results: There were no statistically significant differences between both groups regarding CBC parameters and liver profile ( $p$ value $>0.05)$. There was a statistically significant difference between patients with and without $\mathrm{HCC}$ regarding blood mRNA MMP-12 overexpression ( $p$ value $<0.01$ ), blood mRNA MMP-12, and/or AFP (sensitivity $84.0 \%$, specificity $60.0 \%$, PPV $51.2 \%$, and NPP $88.2 \%)$. The accuracy of mRNA MMP-12 and/or AFP in detection of HCC was $68.0 \%$. Conclusion: Blood mRNA MMP-12 has a good sensitivity and a bad specificity but is accurate in HCC diagnosis. Adding blood mRNA MMP-12 to AFP optimizes the current screening program to improve early diagnosis of $\mathrm{HCC}$ and hence better prognosis.

(c) 2019 S. Karger AG, Basel
\end{abstract}




\section{Introduction}

Hepatocellular carcinoma (HCC) is one of the most common cancers in the world; it represents more than 5\% of all malignances. About 690,000 cases of HCC are diagnosed annually. It is the third leading cause of cancer-related deaths; about 690,000 people die from HCC worldwide [1]. In Egypt, HCC is one of the three frequently diagnosed cancers [2].

Unlike most solid tumors, the coexistence of two life-threatening conditions (cancer and cirrhosis) complicates the prognostic assessments. The prognosis of patients is solely related to tumor stage and liver condition, which simultaneously determine the applicability and efficacy of therapy. Accordingly, early diagnosis is strongly needed, and the prognostication art depends on four tightly related aspects: tumor stage, synthetic power of liver, patient's general condition, and the efficacy of therapeutic modality $[3,4]$.

Alpha-fetoprotein (AFP) and real-time abdominal ultrasound have been used for a long time in the surveillance and diagnosis of HCC. Additionally, AFP can be used in follow-up after locoregional and systemic therapies; however, it is insufficiently sensitive or specific. It is elevated in many settings of various malignancies in addition to HCC, as germ cell tumors, gastric cancer, and intrahepatic cholangiocarcinoma. Its level also increases in nonmalignant lesions as in patients with cirrhosis even in the absence of HCC, as a reflection of the degree of necroinflammatory changes $[5,6]$. So, looking for other tumor markers is mandatory for patients and hepatologists aiming for diagnosis at earlier stages.

The matrix metalloproteinases (MMPs) are a family of zinc-dependent endopeptidase enzymes. Their activity was firstly detected in mouse peritoneal macrophage-conditioned media in 1975 [7].

They are responsible for degradations of elastin and a broad range of matrix and nonmatrix substrates including type IV collagen, type I gelatin, fibronectin, laminin, entactin, vitronectin, proteoglycan, myelin basic protein, and alpha-1 antitrypsin protein [8]. Additionally, they are also linked to tumor invasion and metastasis [9]; however, their association with angiogenesis remains controversial [10]. Cancer invasion and metastasis depend mainly on the degradation of the extracellular matrix. The extracellular proteins are degraded through the proteolytic effect of MMPs.

Many studies have shown the role of overexpressed MMP-1, MMP-2, MMP-9, and MMP-14 in contribution of epithelial-mesenchymal transition-mediated HCC invasion and metastasis $[11,12]$. More than ever, the role of MMP-7 has been discussed. The serum sphingosine1-phosphate level in HCC positively correlated with the serum syndecan-1 level with existing significant inverse correlation between sphingosine-1-phosphate and syndecan-1 in HCC tissues. Sphingosine-1-phosphate induces advanced tumor phenotypes of HCC via establishing MMP-7/syndecan-1/TGF- $\beta 1$ autocrine loop and implicates targetable sphingosine1-phosphate-PI3K/AKT-HPSE-MMP-7 signaling axe in HCC metastasis. However, the role of MMP-12 in cancer progression is still ambiguous, and it has been considered a double-edged sword in tumor progression [13].

Similarly, in HCC, there is positive reciprocal regulation between MMP-8 and TGF- $\beta 1$, which explains the probable molecular mechanism underlying the dysregulation of MMP-8 and TGF- $\beta 1$ in HCC cells. Moreover, the functional interplay between MMP- 8 and TGF- $\beta 1$ contributes to the malignant progression of HCC mainly through the activation of PI3K/Akt/ Rac1 signaling with significant correlation between MMP-8 and TGF- $\beta 1$ overexpression and poor prognosis and metastasis in patients with HCC [11].

MMP-12 was identified and formerly isolated from alveolar macrophages of cigarette smokers [10]. MMP-12 plays an important role in cancer development and progression, and it is highly expressed in a wide range of cancers, including colorectal, gastric, nasopharyngeal, lung cancers, and HCC $[14,15]$. The expression of MMP-12 is strongly associated with in situ 
generation of human angiostatin (potent inhibitor of angiogenesis) that inhibits the growth of tumor metastases by suppression of the neovascularization and increase of apoptosis [16].

The possible carcinogenic role of MMP-12 might be related to the single nucleotide polymorphisms of MMP-12-82A $>\mathrm{G}$ (rs2276109) in the promoter region, which affects transcriptional activity and leads to alterations in MMP-12 gene expression [17].

The aim of the study was to investigate the diagnostic value of blood MMP-12 expression in patients with HCC and the value of adding it to the screening role of AFP.

\section{Subjects and Methods}

\section{Subjects}

This study was carried out from January 2017 to June 2017 with 100 HCC patients aged 47 to 71 years old versus 100 patients with chronic HCV-related liver cirrhosis (without HCC) aged from 45 to 69 years old. We excluded all patients with cirrhosis or non-HCV-related HCC. Informed written consent was obtained from all participants.

Methods

All participants were subjected to history taking and medical examination. HCC was diagnosed depending on laboratory investigations (liver profile, serum AFP, viral markers) and imaging depending mainly on triphasic CT abdomen and dynamic MRI [18]. Patients without HCC were subjected to liver profile, serum AFP, viral markers, and abdominal ultrasound. Triphasic CT and dynamic MRI were done for some cases to exclude HCC if AFP is elevated above $200 \mu \mathrm{g} / \mathrm{dL}$ and/or hepatic focal lesions were seen during ultrasound examination.

All subjects were evaluated for measurement of blood MMP-12: molecular characterization of metalloproteinase-12 expression in all samples by molecular biology techniques: DNA and RNA extraction from the whole blood samples to perform PCR and real-time PCR, respectively.

Specimen Collection

Under complete aseptic technique, $10 \mathrm{~mL}$ of blood was taken from each subject.

\section{Statistical Procedures}

Data was statistically analyzed using SPSS (Statistical Package for Social Sciences) program version 21 for windows, and for all the analyses, a $p$ value $<0.05$ was considered statistically significant:

- $\quad$ Data are shown as mean, range, or value and 95\% confidence interval (95\% CI) and frequency and percent. All data were tested with Kolmogorov-Smirnov $Z$ test and most of them were found normally distributed and so presented with mean \pm SD, and parametric tests on doing association or correlation were used.

- $\quad$ ANOVA test was done to compare three variables: one qualitative variable and the other two quantitative variables of normally distributed variables to detect mean and standard deviation, where LSD test is a post hoc test that was done to detect the relationship between variables within groups.

- Kruskal-Wallis test was done to compare three or more variables: one qualitative variable and the others quantitative variables of non-normally distributed variables to detect mean and standard deviation, where Tamhane post hoc tests were done to detect the relationship between variables within groups.

- $\quad$ ROC curve (receiver operating characteristic curve) was done to detect cut level of any tested variable, where at this level, there is the best sensitivity and specificity cutoff values of the variables for the presence of the disease; moreover, they were used to identify the cutoff of the prevalence-adjusted negative and positive values for the presence of the disease. The validity of the model was measured by means of the concordance statistic (equivalent to the area under the ROC curve, AUC). A model with a $c$ value above 0.7 is considered useful, while a $c$ value between 0.8 and 0.9 indicated excellent diagnostic accuracy. Informed written consents were obtained from all participants.

- Linear regression analysis was performed on factors which were significantly different in correlation to determine equation of regression and to detect factors that are independently associated with the presence of the factor under the study. 
Tumors

\begin{tabular}{l|l}
\hline DOI: 10.1159/000495838 & $\begin{array}{l}\text { C } 2019 \text { S. Karger AG, Basel } \\
\text { www.karger.com/gat }\end{array}$ \\
\hline
\end{tabular}

Elshimi et al.: MMP-12 for HCC

Table 1. CBC, liver profile, and creatinine in the studied groups

\begin{tabular}{|c|c|c|c|c|c|}
\hline Studied variables & Groups & Mean & Std. deviation & $t$ test & $p$ value \\
\hline WBCs & $\begin{array}{l}\text { HCC } \\
\text { LC }\end{array}$ & $\begin{array}{l}5.35 \\
6.69\end{array}$ & $\begin{array}{l}2.24 \\
0.61\end{array}$ & $6.97^{*}$ & 0.000 \\
\hline $\mathrm{HB}$ & $\begin{array}{l}\text { HCC } \\
\text { LC }\end{array}$ & $\begin{array}{l}11.71 \\
13.6\end{array}$ & $\begin{array}{l}1.78 \\
0.55\end{array}$ & 10.09 & 0.000 \\
\hline RBCs & $\begin{array}{l}\text { HCC } \\
\text { LC }\end{array}$ & $\begin{array}{l}3.86 \\
4.47\end{array}$ & $\begin{array}{l}0.68 \\
0.25\end{array}$ & 8.37 & 0.000 \\
\hline Platelets & $\begin{array}{l}\text { HCC } \\
\text { LC }\end{array}$ & $\begin{array}{l}131.42 \\
236.8\end{array}$ & $\begin{array}{l}62.7 \\
29.79\end{array}$ & $10.28^{*}$ & 0.000 \\
\hline PT & $\begin{array}{l}\text { HCC } \\
\text { LC }\end{array}$ & $\begin{array}{l}13.5 \\
12.72\end{array}$ & $\begin{array}{l}0.89 \\
0.69\end{array}$ & 6.91 & 0.000 \\
\hline $\mathrm{PC}$ & $\begin{array}{l}\text { HCC } \\
\text { LC }\end{array}$ & $\begin{array}{l}78.36 \\
89.14\end{array}$ & $\begin{array}{r}11.68 \\
9.73\end{array}$ & 7.09 & 0.000 \\
\hline INR & $\begin{array}{l}\text { HCC } \\
\text { LC }\end{array}$ & $\begin{array}{l}1.25 \\
1.13\end{array}$ & $\begin{array}{l}0.17 \\
0.12\end{array}$ & 5.79 & 0.000 \\
\hline Creatinine & $\begin{array}{l}\text { HCC } \\
\text { LC }\end{array}$ & $\begin{array}{l}0.88 \\
0.75\end{array}$ & $\begin{array}{l}0.37 \\
0.09\end{array}$ & $2.2^{*}$ & 0.03 \\
\hline SGOT & $\begin{array}{l}\text { HCC } \\
\text { LC }\end{array}$ & $\begin{array}{l}51.94 \\
35.32\end{array}$ & $\begin{array}{r}21.98 \\
7.55\end{array}$ & $5.81^{*}$ & 0.000 \\
\hline SGPT & $\begin{array}{l}\text { HCC } \\
\text { LC }\end{array}$ & $\begin{array}{l}51.94 \\
37.94\end{array}$ & $\begin{array}{l}24.2 \\
10.04\end{array}$ & $3.06^{*}$ & 0.002 \\
\hline Total bilirubin & $\begin{array}{l}\text { HCC } \\
\text { LC }\end{array}$ & $\begin{array}{l}0.96 \\
0.68\end{array}$ & $\begin{array}{l}0.31 \\
0.07\end{array}$ & 8.73 & 0.000 \\
\hline Albumin & $\begin{array}{l}\text { HCC } \\
\text { LC }\end{array}$ & $\begin{array}{l}3.35 \\
3.74\end{array}$ & $\begin{array}{l}0.51 \\
0.13\end{array}$ & 7.48 & 0.000 \\
\hline
\end{tabular}

* Mann-Witney test.

\section{Results}

This study was conducted on 2 groups: the first group included 100 patients with HCC, and the second group included 100 patients with liver cirrhosis without HCC. Table 1 represents the differences between the studied groups. There were no statistically significant differences between HCC and cirrhotic patients regarding CBC parameters and liver profile ( $p$ value $<0.01$ ), but no difference was found between all groups regarding serum creatinine ( $p$ value $>0.05$ ).

Table 2 shows the differences between the different groups regarding real-time PCR for HCV, AFP, and real-time PCR for MMP-12. There was statistically significant difference between patients with and without HCC regarding the overexpressed mRNA MMP-12 ( $p$ value $<0.01$ )

Table 3 represents the stepwise linear regression of factors predicting development of HCC. The factors are affecting the development of HCC in patients with cirrhosis by $91 \%$. All these factors are independent predictors of HCC development. 
Tumors

\begin{tabular}{l|l}
\hline DOI: 10.1159/000495838 & $\begin{array}{l}\text { @ } 2019 \text { S. Karger AG, Basel } \\
\text { www.karger.com/gat }\end{array}$ \\
\hline
\end{tabular}

Elshimi et al.: MMP-12 for HCC

Table 2. HCV real-time PCR, MMP-12, and AFP in the studied groups

\begin{tabular}{|c|c|c|c|c|c|}
\hline Studied variables & Groups & Mean & Std. deviation & $\begin{array}{l}\text { Mann-Whitney } \\
\text { test }\end{array}$ & $p$ value \\
\hline RT-PCR for HCV & $\begin{array}{l}\text { HCC } \\
\text { LC }\end{array}$ & $\begin{array}{r}1,310,264.0 \\
216,973.22\end{array}$ & $\begin{array}{r}1,562,167.29 \\
215,559.19\end{array}$ & 6.45 & 0.000 \\
\hline AFP & $\begin{array}{l}\text { HCC } \\
\text { LC }\end{array}$ & $\begin{array}{r}224.43 \\
3.35\end{array}$ & $\begin{array}{r}409.6 \\
1.33\end{array}$ & 10.19 & 0.000 \\
\hline RT-PCR for MMP-12 & $\begin{array}{l}\text { HCC } \\
\text { LC }\end{array}$ & $\begin{array}{l}3.27 \\
2.53\end{array}$ & $\begin{array}{l}5.89 \\
3.79\end{array}$ & 2.28 & 0.02 \\
\hline
\end{tabular}

Table 3. Stepwise linear regression of factors predicting development of HCC

\begin{tabular}{|c|c|c|c|c|c|c|}
\hline \multirow[t]{2}{*}{ Model } & \multicolumn{2}{|c|}{$\begin{array}{l}\text { Unstandardized } \\
\text { coefficients }\end{array}$} & \multirow[t]{2}{*}{$p$ value } & \multirow[t]{2}{*}{ OR } & \multicolumn{2}{|c|}{$\begin{array}{l}95.0 \% \text { confidence } \\
\text { interval for OR }\end{array}$} \\
\hline & $\mathrm{B}$ & Std. error & & & $\begin{array}{l}\text { lower } \\
\text { bound }\end{array}$ & $\begin{array}{l}\text { upper } \\
\text { bound }\end{array}$ \\
\hline$R^{2}$ & \multicolumn{6}{|c|}{0.91} \\
\hline B (constant) & 1.888 & & & & & \\
\hline PLT & -0.002 & 0.000 & 0.000 & 0.218 & -0.002 & -0.001 \\
\hline Age & -0.041 & 0.003 & 0.000 & 0.649 & -0.047 & -0.036 \\
\hline Albumin & 0.406 & 0.067 & 0.000 & 0.341 & 0.273 & 0.539 \\
\hline RT-PCR for MMP-12 & -0.050 & 0.004 & 0.000 & 0.499 & -0.057 & -0.043 \\
\hline WBCs & 0.065 & 0.012 & 0.000 & 0.229 & 0.042 & 0.088 \\
\hline $\mathrm{TB}$ & -0.697 & 0.132 & 0.000 & 0.367 & -0.957 & -0.437 \\
\hline SGOT & -0.022 & 0.002 & 0.000 & 0.794 & -0.025 & -0.018 \\
\hline SGPT & 0.012 & 0.001 & 0.000 & 0.488 & 0.010 & 0.015 \\
\hline RBCs & 0.454 & 0.083 & 0.000 & 0.542 & 0.290 & 0.618 \\
\hline Creatinine & 0.252 & 0.048 & 0.000 & 0.140 & 0.158 & 0.346 \\
\hline RT-PCR & -5.46 & 0.000 & 0.000 & 0.135 & 0.000 & 0.000 \\
\hline MMP-12 & -0.214 & 0.038 & 0.000 & 0.205 & -0.288 & -0.140 \\
\hline $\mathrm{HB}$ & -0.104 & 0.034 & 0.003 & 0.336 & -0.170 & -0.037 \\
\hline AFP & 0.000 & 0.000 & 0.012 & 0.092 & 0.000 & 0.000 \\
\hline
\end{tabular}

Regression equation: HCC $=$ B0 (2.89) $-0.002 \times$ PLT $-0 / 04 \times$ age $+0.41 \times$ albumin $-0.05 \times$ RT-PCR for MMP-12 $+0.06 \times$ WBCs $-0.69 \times \mathrm{TB}-0.02 \times \mathrm{SGOT}+0.01 \times \mathrm{SGPT}+0.45 \times \mathrm{RBCs}+0.25 \times$ creatinine $-5.46 \times$ RT-PCR $-0.2 \times$ MMP-12 $-0.1 \times \mathrm{HB}+0.0001 \times \mathrm{AFP}$.

Table 4. Sensitivity and specificity of MMP-12 in the studied groups

\begin{tabular}{llllllll}
\hline Studied variables & Sensitivity & Specificity & AUC & Accuracy & $p$ value & SE & CI \\
\hline $\begin{array}{c}\text { RT-PCR for MMP-12 } \\
\text { Cut level = } 0.7088\end{array}$ & $72.0 \%$ & $60.0 \%$ & 0.68 & $70.9 \%$ & $<0.01^{* *}$ & 0.03 & $0.62-0.74$ \\
\hline
\end{tabular}

Table 4 and Figure 1 represent the sensitivity, specificity, and accuracy of blood MMP-12 alone in the diagnosis of HCC: The sensitivity, specificity, AUC, and accuracy were 72.0, 60.0, 68 , and $70.9 \%$, respectively ( $p$ value $<0.01$ ). 
Table 5. MMP-12 and/or AFP in patients with and without HCC

Fig. 1. ROC curve for the sensitiv-

\begin{tabular}{lccr}
\hline MMP-12 and/or AFP & \multicolumn{2}{c}{ Clinical diagnosis } & \multirow{2}{*}{ Total } \\
\cline { 2 - 3 } as a screening tool & HCC & non-HCC & \\
\hline Positive & 84 & 56 & 140 \\
Negative & 16 & 44 & 60 \\
\hline Total & 100 & 100 & 200 \\
\hline
\end{tabular}
ity and specificity of MMP-12 in the diagnosis of HCC.

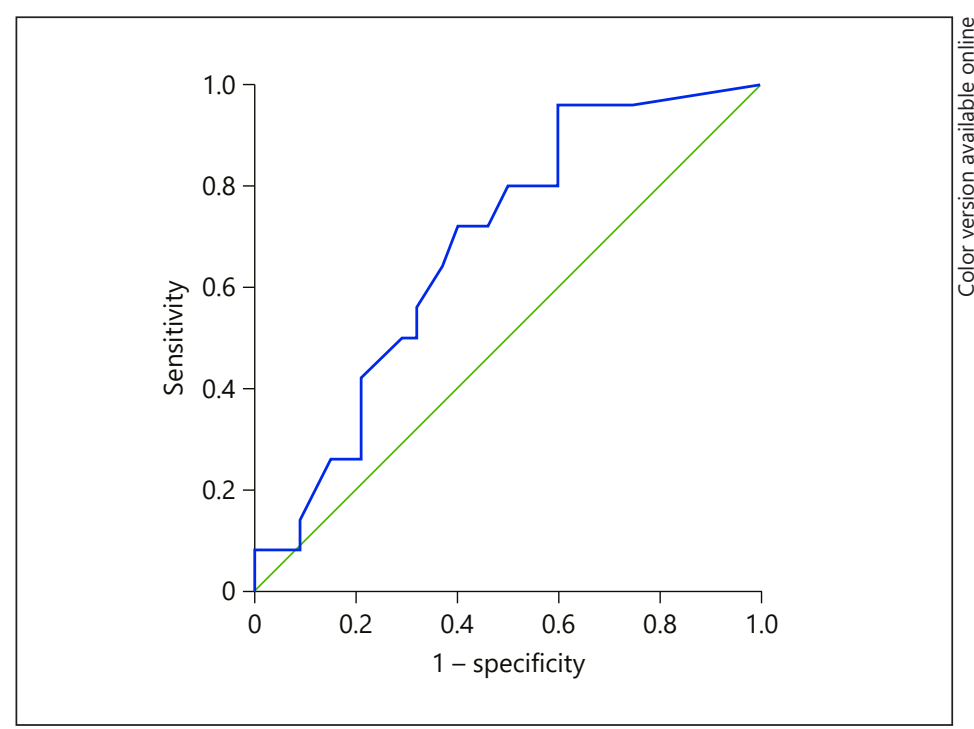

Table 5 represents the diagnostic value of blood mRNA MMP-12 and/or AFP for HCC: the sensitivity, specificity, PPV, NPP, and accuracy were $84.0,60.0,51.2,88.2$, and 68.0\%, respectively.

\section{Discussion}

Diagnosis of HCC at an earlier stage of the disease is the Achilles heel of prognosis and guides treatment decisions. The 4 key factors that may affect the prognosis include: tumor stage at diagnosis, overall health of the patient, hepatic synthetic function, and efficacy of treatment [18]. So, patients and clinicians are in need for an ideal diagnostic marker for accurate detection of HCC in high-risk patients at early stages.

Tumor biomarkers are indicators of a physiological status; they are detectable in serum, urine, or tissues of patients with cancer. Ideal biomarkers and their presence and changes in body fluids can reflect the disease occurrence, progression, recurrence, and prognosis.

To the best of our knowledge, our study was the first one that discussed the diagnostic value of adding the overexpressed blood mRNA MMP-12 and or AFP in the diagnosis of HCC. In our series, the overexpressed MMP-12 had a good sensitivity and a bad specificity but was accurate in the diagnosis of HCC in patients with chronic HCV-related cirrhosis. The diagnosis of HCC improved significantly with adding MMP-12 to AFP more than using AFP alone ( $p$ value $<0.01$ ). The sensitivity and specificity of MMP-12 and/or AFP were 84.0 and $60.0 \%$, respectively, positive and negative predictive values of MMP-12 and/or AFP were 51.2 and 
88.2\%, respectively, and the accuracy of MMP-12 and/or AFP was $68.0 \%$. While the sensitivity and specificity of MMP-12 and AFP were 58.0 and 78.0\%, respectively, the positive and negative predictive values of MMP-12 and AFP were 56.9 and $78.8 \%$, respectively. Finally, the accuracy of MMP-12 and AFP was $71.3 \%$.

Many studies discussed the use of MMPs in HCC, GIT cancers, and other cancers. Liu et al. [19] hypothesized that the surrounding tumor-associated stromal cells play a crucial role in 14-3-3 $\sigma$-regulated HCC cell invasion. They incubated H68 fibroblasts, THP-1, and phorbol12-myristate-13-acetate (PMA)-treated THP-1 (PMA-THP-1) cells with conditioned media of

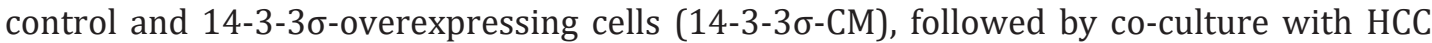
cells. HCC cells significantly enhanced their invasive power compared with control CM-treated

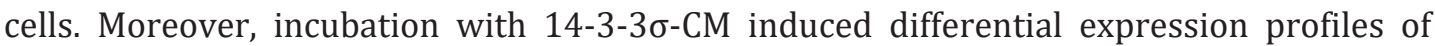
MMPs in fibroblasts (MMP-1, 2, 9, 12, and 14), THP-1 (MMP-1 and 12), and PMA-THP-1 cells (MMP-2, 12, and 14) [19].

$\mathrm{Ng}$ et al. [20] studied the significance and prognostic value of MMP-12 expression in 139 pairs of tumor and non-tumor liver tissues of HCC patients after hepatectomy. They found that the PCR MMP-12 mRNA was significantly elevated in tumor tissues compared to nontumor and normal liver tissues. Overexpression of MMP-12 mRNA significantly correlated with presence of venous infiltration, high serum AFP level, early tumor recurrence, and poor overall survival of patients. Moreover, MMP-12 mRNA was an independent factor in predicting overall survival after hepatectomy [20].

Similarly, Gorrin Rivas et al. [21] studied the correlation between human macrophage metalloelastase gene expression and angiostatin production using the mRNA expression and angiostatin generation in tumorous and non-tumorous tissues obtained from 40 HCC patients after partial hepatectomy. The mRNA was detected in 25 out of $40 \mathrm{HCC}$ tissues. They concluded that MMP gene was expressed by HCC cells, and it can be responsible for the angiostatin generation by such tumor cells and may serve as a prognostic marker in HCC patients [21].

Miyoshi et al. [22] examined whether Snail gene expression correlates with cancer invasion and prognosis in HCC. RT-PCR was performed to evaluate Snail, E-cadherin, and MMP mRNA expressions in 47 ordinary HCC tissues. In the HCC tissues, Snail expression was significantly correlated with portal vein invasion, intrahepatic metastasis, correlation with MT1-MMP expression, and poorer prognosis by upregulating MMP expression [22].

The functional polymorphisms of MMP-12 may contribute to interindividual differences in susceptibility to a wide spectrum of cancers. MMPs are plausible HCC candidate genes; however, Zhai et al. [23] estimated whether the MMP polymorphisms have any bearing role on the risk of HCC development. They focused on seven promoters of six MMP genes: MMP-1 -1607 1G/2G (rs1799750), MMP-2 C-1306T (rs243865) and C-735T (rs2285053), MMP-3 -1612 5A/6A (rs3025058), MMP-9 C-1562T (rs3918242), MMP-12 G-82A (rs2276109), and MMP-13 G-77A (rs17860523), respectively. Their results suggested that the seven functional polymorphisms in the promoters of MMP-1, MMP-2, MMP-3, MMP-9, MMP-12, and MMP-13 did not significantly confer an increased risk of HCC [20]. Similar data were found in colorectal cancer [24] and gastric carcinoma [25]. Similar data were obtained in many cancers outside GIT [26-28].

From the above shown data, MMP-12 might be a universal target for diagnosis and prognosis of cancer and might be used as a promising screening marker in looking for hidden malignancies. Furthermore MMP-12 may play a crucial role in anticancer therapy. Fucosyltransferase IV (FUT4) has been implicated in cell adhesion, motility, and tumor progression in human epidermoid carcinoma A431 cells. So, treatment with EGF resulted in an alteration of cell morphology and induced an increase in the expression of MMP-12 [29].

Additionally, inhibition of MMP synthesis may be targeted as an anticancer therapy. Several agents have been developed that block the MMPs and prevent them from interacting 
with the molecules directing their activities to the cell surface or inhibiting their enzymatic activity. It can also be reduced indirectly, by inhibition of the signal-transduction pathways that induce MMP transcription by inhibiting tyrosine kinase receptor signaling [30-33].

The strengths of this study include its novelty in discussing the diagnostic value of overexpressed MMP-12 and its value in optimizing the role of AFP and abdominal ultrasound in surveillance for HCC in patients with cirrhosis to increase the diagnostic yield of them in diagnosing HCC at earlier stages.

The limitations of this study include the relatively small number of patients, the followup after response by locoregional or systemic therapies was not addressed, and the segregation of early and late stages was not studied.

\section{Conclusion}

Blood mRNA MMP-12 has a good sensitivity and a bad specificity but is accurate in diagnosing HCC. Adding blood mRNA MMP-12 to AFP in the screening programs of HCC in cirrhotic patients improves early diagnosis and hence better prognosis.

\section{References}

1 Jemal A, Bray F, Center MM, Ferlay J, Ward E, Forman D. Global cancer statistics. CA Cancer J Clin. 2011 Mar-Apr;61(2):69-90.

2 Abdel-Wahab M, el-Enein AA, Abou-Zeid M, el-Fiky A, Abdallah T, Fawzy M, et al. Hepatocellular carcinoma in Mansoura-Egypt: experience of 385 patients at a single center. Hepatogastroenterology. 2000 May-Jun; 47(33):663-8.

3 Llovet JM, Di Bisceglie AM, Bruix J, Kramer BS, Lencioni R, Zhu AX, et al.; Panel of Experts in HCC-Design Clinical Trials. Design and endpoints of clinical trials in hepatocellular carcinoma. J Natl Cancer Inst. 2008 May; 100(10):698-711.

4 Mukozu T, Nagai H, Matsui D, Kanekawa T, Sumino Y. Serum VEGF as a tumor marker in patients with HCVrelated liver cirrhosis and hepatocellular carcinoma. Anticancer Res. 2013 Mar;33(3):1013-21.

5 Chauhan R, Lahiri N. Tissue- and Serum-Associated Biomarkers of Hepatocellular Carcinoma. Biomark Cancer. 2016 Jul 4;8(Suppl 1):37-55.

6 Gonzalez SA, Keeffe EB. Diagnosis of hepatocellular carcinoma: role of tumor markers and liver biopsy. Clin Liver Dis. 2011 May;15(2):297-306.

7 Werb Z, Gordon S. Secretion of a specific collagenase by stimulated macrophages. J Exp Med. 1975 Aug;142(2): 346-60.

8 Banda MJ, Werb Z. Mouse macrophage elastase. Purification and characterization as a metalloproteinase. Biochem J. 1981 Feb;193(2):589-605.

9 Shapiro SD, Kobayashi DK, Ley TJ. Cloning and characterization of a unique elastolytic metalloproteinase produced by human alveolar macrophages. J Biol Chem. 1993 Nov;268(32):23824-9.

10 Sica A. Role of tumour-associated macrophages in cancer-related inflammation. Exp Oncol. 2010 Sep;32(3): 153-8.

11 Casazza A, Di Conza G, Wenes M, Finisguerra V, Deschoemaeker S, Mazzone M. Tumor stroma: a complexity dictated by the hypoxic tumor microenvironment. Oncogene. 2014 Apr;33(14):1743-54.

12 Lempinen M, Lyytinen I, Nordin A, Tervahartiala T, Mäkisalo H, Sorsa T, et al. Prognostic value of serum MMP-8, -9 and TIMP-1 in patients with hepatocellular carcinoma. Ann Med. 2013 Nov;45(7):482-7.

13 Wang YH, Sui XM, Sui YN, Zhu QW, Yan K, Wang LS, et al. BRD4 induces cell migration and invasion in HCC cells through MMP-2 and MMP-9 activation mediated by the Sonic hedgehog signaling pathway. Oncol Lett. 2015 Oct;10(4):2227-32.

14 Zeng Y, Yao X, Chen L, Yan Z, Liu J, Zhang Y, et al. Sphingosine-1-phosphate induced epithelial-mesenchymal transition of hepatocellular carcinoma via an MMP-7/ syndecan-1/TGF- $\beta$ autocrine loop. Oncotarget. 2016 Sep;7(39):63324-37.

15 Powell WC, Matrisian LM. Complex roles of matrix metalloproteinases in tumor progression. Curr Top Microbiol Immunol. 1996;213(Pt 1):1-21.

16 Gorrin Rivas MJ, Arii S, Furutani M, Harada T, Mizumoto M, Nishiyama H, et al. Expression of human macrophage metalloelastase gene in hepatocellular carcinoma: correlation with angiostatin generation and its clinical significance. Hepatology. 1998 Oct;28(4):986-93. 
17 Yang XS, Liu SA, Liu JW, Yan Q. Fucosyltransferase IV enhances expression of MMP-12 stimulated by EGF via the ERK1/2, p38 and NF- $\mathrm{B}$ pathways in A431 cells. Asian Pac J Cancer Prev. 2012;13(4):1657-62.

18 Bruix J, Sherman M, Llovet JM, Beaugrand M, Lencioni R, Burroughs AK, et al.; EASL Panel of Experts on HCC; European Association for the Study of the Liver. Clinical management of hepatocellular carcinoma. Conclusions of the Barcelona-2000 EASL conference. J Hepatol. 2001 Sep;35(3):421-30.

19 Liu CC, Chang TC, Lin YT, Yu YL, Ko BS, Sung LY, et al. Paracrine regulation of matrix metalloproteinases contributes to cancer cell invasion by hepatocellular carcinoma-secreted 14-3-3б. Oncotarget. 2016 Jun; 7(24):36988-99.

20 Ng KT, Qi X, Kong KL, Cheung BY, Lo CM, Poon RT, et al. Overexpression of matrix metalloproteinase-12 (MMP-12) correlates with poor prognosis of hepatocellular carcinoma. Eur J Cancer. 2011 Oct;47(15):2299_ 305.

21 Gorrin Rivas MJ, Arii S, Furutani M, Harada T, Mizumoto M, Nishiyama H, et al. Expression of human macrophage metalloelastase gene in hepatocellular carcinoma: correlation with angiostatin generation and its clinical significance. Hepatology. 1998 Oct;28(4):986-93.

22 Miyoshi A, Kitajima Y, Kido S, et al. Snail accelerates cancer invasion by up regulating MMP expression and is associated with poor prognosis of hepatocellular carcinoma metastasis, and poor prognosis. Br J Cancer. 2005; 92:252-8.

23 Zhai Y, Qiu W, Dong XJ, Zhang XM, Xie WM, Zhang HX, et al. Functional polymorphisms in the promoters of MMP-1, MMP-2, MMP-3, MMP-9, MMP-12 and MMP-13 are not associated with hepatocellular carcinoma risk. Gut. 2007 Mar;56(3):445-7.

24 Woo M, Park K, Nam J, Kim JC. Clinical implications of matrix metalloproteinase-1, -3, -7, -9, -12, and plasminogen activator inhibitor-1 gene polymorphisms in colorectal cancer. J Gastroenterol Hepatol. 2007 Jul; 22(7):1064-70.

25 Li Y, Sun DL, Duan YN, Zhang XJ, Wang N, Zhou RM, et al. Association of functional polymorphisms in MMPs genes with gastric cardia adenocarcinoma and esophageal squamous cell carcinoma in high incidence region of North China. Mol Biol Rep. 2010 Jan;37(1):197-205.

26 Kader AK, Shao L, Dinney CP, Schabath MB, Wang Y, Liu J, et al. Matrix metalloproteinase polymorphisms and bladder cancer risk. Cancer Res. 2006 Dec;66(24):11644-8.

27 Li Y, Jia JH, Kang S, Zhang XJ, Zhao J, Wang N, et al. The functional polymorphisms on promoter region of matrix metalloproteinase-12, -13 genes may alter the risk of epithelial ovarian carcinoma in Chinese. Int J Gynecol Cancer. 2009 Jan;19(1):129-33.

28 Su L, Zhou W, Asomaning K, Lin X, Wain JC, Lynch TJ, Liu G, Christiani DC. Genotypes and haplotypes of matrix metalloproteinase 1, 3 and 12 genes and the risk of lung cancer. Carcinogenesis. 2006 May;27(5):1024-9.

29 Noonberg SB, Benz CC. Tyrosine kinase inhibitors targeted to the epidermal growth factor receptor subfamily: role as anticancer agents. Drugs. 2000 Apr;59(4):753-67.

30 Hirte H, Goel R, Major P, Seymour L, Huan S, Stewart D, et al. A phase I dose escalation study of the matrix metalloproteinase inhibitor BAY 12-9566 administered orally in patients with advanced solid tumours. Ann Oncol. 2000 Dec;11(12):1579-84.

31 Hidalgo M, Eckhardt SG. Development of matrix metalloproteinase inhibitors in cancer therapy. J Natl Cancer Inst. $2001 \mathrm{Feb}$; 93(3):178-93.

32 Moore MJ, Hamm J, Dancey J, Eisenberg PD, Dagenais M, Fields A, et al.; National Cancer Institute of Canada Clinical Trials Group. Comparison of gemcitabine versus the matrix metalloproteinase inhibitor BAY 12-9566 in patients with advanced or metastatic adenocarcinoma of the pancreas: a phase III trial of the National Cancer Institute of Canada Clinical Trials Group. J Clin Oncol. 2003 Sep;21(17):3296-302.

33 Hidalgo M, Eckhardt SG. Development of matrix metalloproteinase inhibitors in cancer therapy. J Natl Cancer Inst. $2001 \mathrm{Feb}$;93(3):178-93. 